\title{
A simple method for the separation and quantification of urinary porphyrins
}

\author{
DT LEAHY, TG BRIEN \\ From the Department of Pathology, University College, Earlsfort Terrace, Dublin 2, Ireland
}

SUMMARY A simple routine method for the separation and quantification of urinary coproporphyrin and uroporphyrin using anion-exchange resin columns is described.

The coproporphyrin is first removed from the urine by ether extraction. The anion exchange resin column is then used to isolate the uroporphyrin from the aqueous residue.

The proposed method is compared with an existing method developed by Rimington in terms of recovery and reproducibility. Results from 15 urine specimens analysed by both methods are compared.

The proposed method yielded lower values for coproporphyrin and higher values for uroporphyrin than the established method, but there was a good correlation between the two methods. This and its relative simplicity make it suitable for routine use.

Although simple screening tests for the presence of raised porphyrin concentrations in urine are available these do not separate uroporphyrin from coproporphyrin and hence quantification of the individual porphyrins present in the sample cannot be achieved.' However, since porphyrins exhibit a strong Soret band absorbance between 400 and 410 $\mathrm{nm}$, spectrophotometry of extracts of urine may give an indication of the predominant porphyrin present in the sample. The absorbance peak occurs at about $401 \mathrm{~nm}$ for coproporphyrin and around $406 \mathrm{~nm}$ for uroporphyrin.

Quantification of urinary copro- and uroporphyrins can be achieved using the method of Rimington. ${ }^{2}$ However, this method involves multiple extraction with several solvents, is long and tedious and is unsuitable for handling more than a few specimens at a time. In this paper we describe a simple and rapid procedure for the quantitative estimation of uroporphyrin and coproporphyrin in the same urine sample employing only one solvent extraction and ionexchange chromatography.

\section{Material and methods}

Coproporphyrin and uroporphyrin standards were purchased from Sigma Ltd, Poole, England. Porphyrin chromatography columns containing $1 \mathrm{~g}$ of

Accepted for publication 14 April 1982
Dowex $1 \times 8,50-100$ mesh resin were obtained from Bio Rad Laboratories, Richmond, California.

\section{RIMINGTON'S METHOD}

This is the classical solvent extraction method of Rimington (1971) as recommended by the Association of Clinical Pathologists (ACP). It was slightly modified by the substitution of $n$-butanol extraction at $\mathrm{pH} 3 \cdot 2$ for cyclohexanone in the final stages.

Urine $(12.5 \mathrm{ml})$ is pipetted into a separating funnel and acidified with $1.25 \mathrm{ml}$ of glacial acetic acid. The coproporphyrins are extracted twice with $25 \mathrm{ml}$ of ether. The ether extracts are combined and the aqueous phase is retained for determination of uroporphyrin.

The combined ether extracts are washed with successive portions of dilute sodium acetate solution until the aqueous phase no longer shows red fluorescence under ultraviolet light. These washings are combined, twice shaken with an equal volume of fresh ether and then added to the original aqueous urine residue. The ether is combined with the initial ether extracts and the whole washed with dilute iodine solution and then with distilled water.

Coproporphyrin is extracted from the ether by shaking with successive $2 \mathrm{ml}$ portions of $5 \%$ hydrochloric acid until the extract no longer shows red fluorescence under ultraviolet light. The acid extract is quantified spectrophotometrically.

The combined aqueous phases are brought to a $\mathrm{pH}$ of $3 \cdot 2$ and extracted twice with $n$-butanol. Two 1232 
volumes of ether are added to the pooled butanol extracts and uroporphyrin is extracted by shaking with successive $2 \mathrm{ml}$ volumes of $5 \% \mathrm{HCl}$ until the extracts no longer show red fluorescence. The uroporphyrin content of the pooled acid extracts is measured by spectrophotometry.

\section{PROPOSED METHOD}

The proposed method is as follows: an aliquot of the urine is acidified with glacial acetic acid to between $\mathrm{pH} 4 \cdot 0$ and $\mathrm{pH} 4 \cdot 5$. The acidified urine $(10 \mathrm{ml})$ and 3 $\mathrm{ml}$ of acetate buffer ( $\mathrm{pH} 4 \cdot 8,4.5 \mathrm{M}$ ) are added to a separating funnel and extracted twice with $15 \mathrm{ml}$ of ether to remove the coproporphyrins. The aqueous phase is reserved for further treatment and the combined ether extracts are washed with $10 \mathrm{ml}$ of distilled water.

The coproporphyrin is extracted from the ether with $2 \times 2 \mathrm{ml}$ of $0.1 \mathrm{~N} \mathrm{HCl}$. The absorbance of the pooled extracts is read at $380 \mathrm{~nm}, 430 \mathrm{~nm}$ and at the absorbance peak (about $401 \mathrm{~nm}$ ).

Of the aqueous residue, $4 \mathrm{ml}$ is applied to the ion-exchange column. The column is allowed to drain and is then washed with $10 \mathrm{ml}$ distilled water. Uroporphyrin is eluted with $2 \times 2 \mathrm{ml}$ of $3 \mathrm{~N} \mathrm{HCl}$ and the absorbance of the eluate is measured at $380 \mathrm{~nm}$, $430 \mathrm{~nm}$ and at the peak absorbance (around $406 \mathrm{~nm}$ ).

\section{Calculations}

$\mathrm{A}^{\max }=$ peak absorbance

$A^{k}=2 A^{\max }-\left(A^{380}+A^{430}\right)$

With and Pedersen, ${ }^{3}$ from studies of purified porphyrins, derive calculation factors $(f)$ where $f \times$ $A^{k}$ gives the concentration of the porphyrin in $\mu \mathrm{g} / 100$ $\mathrm{ml}$. For coproporphyrin in $0.1 \mathrm{~N} \mathrm{HCl} f=72.9$ and for

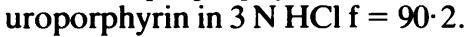

Urinary coproporphyrin $(\mu \mathrm{g} / 100 \mathrm{ml})$ :

$$
\begin{aligned}
& \mathrm{A}^{\mathrm{k}} \times 72.9 \times \frac{\text { volume of acid extract }(4 \mathrm{ml})}{\text { volume of urine taken }(10 \mathrm{ml})}=A^{\mathrm{k}} \times 29 \cdot 2 \\
& \begin{array}{c}
\text { Urinary uroporphyrin }(\mu \mathrm{g} / 100 \mathrm{ml}): \\
\text { original urine volume }(10 \mathrm{ml})
\end{array} \\
& \mathrm{A}^{\mathrm{k}} \times 90.2 \times \frac{+ \text { buffer }(3 \mathrm{ml})}{\text { original urine volume }(10 \mathrm{ml})}=A^{\mathrm{k}} \times 117 \cdot 3
\end{aligned}
$$

No allowance is made in the calculations for incomplete extraction of the porphyrins.

To convert to SI units $(\mu \mathrm{mol} / 1)$ multiply by 0.0153 for coproporphyrin and $0 \cdot 012$ for uroporphyrin.

Recovery experiments were performed by adding either coproporphyrin or uroporphyrin standard to urine low in porphyrins. The concentration of the stock standard was determined in dilute $\mathrm{HCl}$ using a Beckman DU spectrophotometer immediately before addition to the urine, which was then analysed by the relevant method. Coproporphyrin and uropor- phyrin were determined by the proposed method on random day urine samples from 30 healthy males aged 18 to 40 years. Samples from 15 patients with raised porphyrins on the initial screen or in whom individual porphyrins had been specifically requested were investigated using both methods. Not all of these patients were subsequently confirmed as suffering from porphyria.

\section{Results}

\section{RIMINGTON'S METHOD}

Mean recovery of coproporphyrin added to normal urine in amounts from $0.038 \mu \mathrm{mol} / 1$ to $0.305 \mu \mathrm{mol} / 1$ was $106 \cdot 2 \%$ while mean recovery of uroporphyrin added in amounts varying from $0.119 \mu \mathrm{mol} / 1$ to 0.894 $\mu \mathrm{mol} / 1$ was $60.9 \%$. (See Tables 1 and 2.)

\section{PROPOSED METHOD}

Within-batch reproducibility of the proposed method was assessed on a urine with an endogenous coproporphyrin level of $0 \cdot 24 \mu \mathrm{mol} / 1$ and an endogenous uroporphyrin level of $1.00 \mu \mathrm{mol} / 1$. The $\mathrm{CV}$ for coproporphyrin was $1.57 \%$ and for uroporphyrin $2 \cdot 18 \%(n=10)$. Between-batch reproducibility on another urine with mean coproporphyrin and uroporphyrin levels by this method of $0 \cdot 18 \mu \mathrm{mol} / 1$ and $1.02 \mu \mathrm{mol} / 1$ respectively was $4.2 \%$ for coproporphyrin and $7 \cdot 2 \%$ for uroporphyrin $(n=10)$.

Mean recovery of coproporphyrin added to normal urine at concentrations ranging from $0.038 \mu \mathrm{mol} / 1$ to $0.305 \mu \mathrm{mol} / 1$ was $67 \%$ while the mean recovery of uroporphyrin added in concentrations from $0 \cdot 104$ $\mu \mathrm{mol} / 1$ to $0.835 \mu \mathrm{mol} / 1$ was $83.6 \%$. (See Tables 1 and 2.)

\section{LINEARITY}

Using pure standards in acid solution porphyrin concentration was linear with absorbance up to 1.53 $\mu \mathrm{mol} / 1$ for coproporphyrin and $1.94 \mu \mathrm{mol} / 1$ for uroporphyrin. This is in agreement with Rimington ${ }^{4}$ who found that porphyrins in acid solution obey Beer's Law up to an absorbance of about 1.0.

\section{REFERENCE RANGE}

For random urine specimens mean coproporphyrin level was $0.053 \pm 0.03 \mu \mathrm{mol} / 1$ with an upper $95 \%$ limit of $0 \cdot 113 \mu \mathrm{mol} / 1$ and mean uroporphyrin was $0.009 \pm 0.008 \mu \mathrm{mol} / 1$, upper reference limit 0.025 $\mu \mathrm{mol} / 1$.

These results are in good agreement with the range quoted by Fogstrup and With ${ }^{5}$ who found an upper reference limit of $0 \cdot 155 \mu \mathrm{mol} / 1$ for total porphyrin in random urine. Values for coproporphyrin and uroporphyrin in random urine have not, to our knowledge, been cited in the literature. 
Table 1 Recovery of coproporphyrin added to urine low in porphyrins

\begin{tabular}{|c|c|c|c|c|c|}
\hline \multicolumn{6}{|c|}{ Coproporphyrin ( $\mu \mathrm{mol} / \mathrm{l})$} \\
\hline \multicolumn{3}{|c|}{ Rimington's method } & \multicolumn{3}{|c|}{ Proposed method } \\
\hline Added & Recovered & $\begin{array}{l}\% \\
\text { recovery }\end{array}$ & Added & Recovered & $\begin{array}{l}\% \\
\text { recovery }\end{array}$ \\
\hline $\begin{array}{l}0.038 \\
0.076 \\
0.153 \\
0.244 \\
0.305\end{array}$ & $\begin{array}{l}0.040 \\
0.081 \\
0.158 \\
0.267 \\
0.322\end{array}$ & $\begin{array}{l}104 \\
106 \\
103 \\
109 \\
105\end{array}$ & $\begin{array}{l}0 \cdot 038 \\
0 \cdot 076 \\
0 \cdot 153 \\
0 \cdot 191 \\
0 \cdot 305\end{array}$ & $\begin{array}{l}0 \cdot 024 \\
0 \cdot 050 \\
0 \cdot 105 \\
0 \cdot 119 \\
0 \cdot 212\end{array}$ & $\begin{array}{l}64 \\
66 \\
69 \\
62 \\
70\end{array}$ \\
\hline
\end{tabular}

Table 2 Recovery of uroporphyrin added to urine low in porphyrins

\begin{tabular}{|c|c|c|c|c|c|}
\hline \multicolumn{6}{|c|}{ Uroporphyrin ( $\mu \mathrm{mol} / \mathrm{l})$} \\
\hline \multicolumn{3}{|c|}{ Rimington's method } & \multicolumn{3}{|c|}{ Proposed method } \\
\hline Added & Recovered & $\begin{array}{l}\% \\
\text { recovery }\end{array}$ & Added & Recovered & $\begin{array}{l}\% \\
\text { recovery }\end{array}$ \\
\hline $\begin{array}{l}(1) .119 \\
0.3(14 \\
0.6(1) \\
0.894\end{array}$ & $\begin{array}{l}0.076 \\
0 \cdot 190 \\
0 \cdot 384 \\
0.532\end{array}$ & $\begin{array}{l}64 \\
62 \\
63 \\
58\end{array}$ & $\begin{array}{l}0 \cdot 104 \\
0 \cdot 209 \\
0.418 \\
0.835\end{array}$ & $\begin{array}{l}0 \cdot 085 \\
0 \cdot 147 \\
0 \cdot 326 \\
0 \cdot 750\end{array}$ & $\begin{array}{l}82 \\
71 \\
78 \\
90\end{array}$ \\
\hline
\end{tabular}

The reference range quoted by Rimington is that of Fernandez, Henry and Goldenberg. ${ }^{6}$ These authors used 24-hour urine and so their range is not strictly comparable with ours.

However, if we extrapolate our range on the basis of an arbitrary 24-hour urine volume of $1500 \mathrm{ml} \mathrm{a}$ relative comparison with Rimington's range may be made. On this basis our range gives an upper reference limit of $111 \mu \mathrm{g} / 24 \mathrm{~h}$ for coproporphyrin and 30 $\mu \mathrm{g} / 24 \mathrm{~h}$ for uroporphyrin as against Rimington's upper limits of $161 \mu \mathrm{g} / 24 \mathrm{~h}$ and $30 \mu \mathrm{g} / 24 \mathrm{~h}$ respectively.

Results for the 15 patients' urines analysed by both methods are compared in Figs 1 and 2.

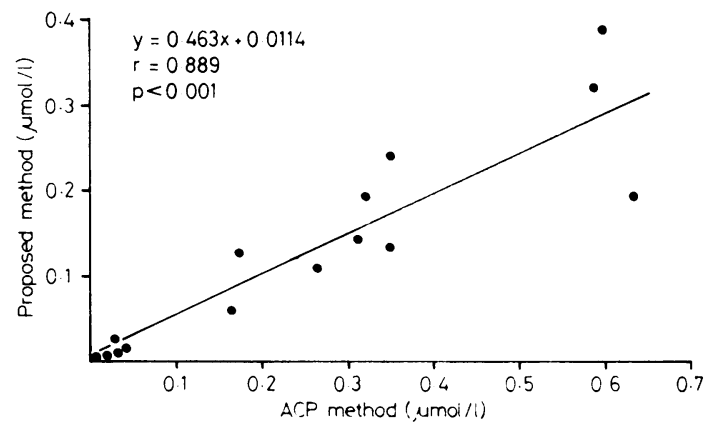

Fig. 1 Comparison of coproporphyrin concentrations in 15 patient urines as assessed by Rimington's ACP method and the proposed method.
Although mean coproporphyrin levels by the proposed method were substantially lower than those found by Rimington's method, a good correlation $\overrightarrow{0}$ was obtained between the two methods $r=0.89$

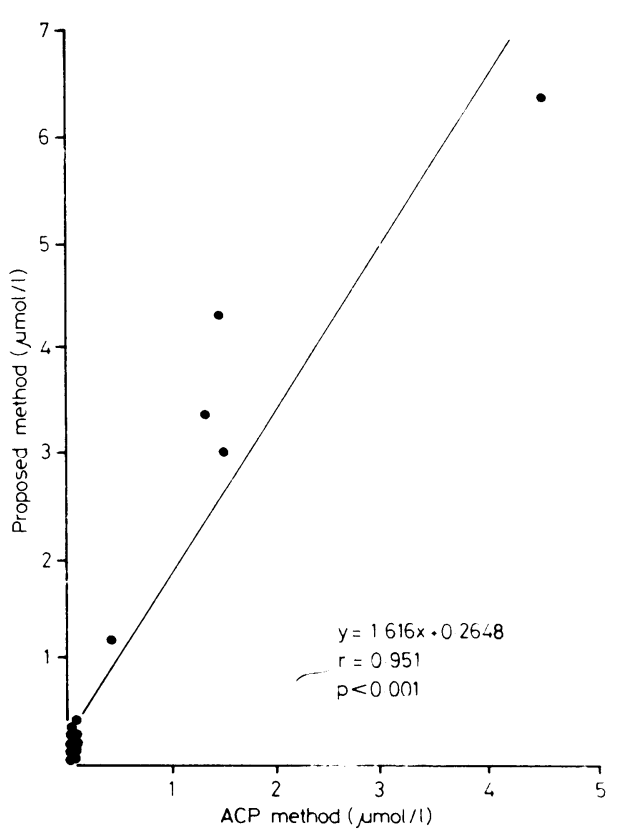

Fig. 2 Comparison of uroporphyrin concentrations in 15 patient urines as assessed by Rimington's ACP method and the proposed method. 
$p<0.001$. In the case of uroporphyrin the mean values by the proposed method were higher than Rimington's method but once again a good correlation was obtained $\mathrm{r}=0.951, \mathrm{p}<0 \cdot 001$.

Of the 15 urines analysed by the proposed method nine were within the reference range, five were typical of porphyria cutanea tarda and one was indicative of variegate porphyria. Analysis of the series by Rimington's method gave the same diagnostic conclusions. The diagnosis of porphyria was supported in each case by clinical information.

\section{Discussion}

Recoveries of added porphyrins mentioned in the literature vary. With ${ }^{7}$ reported coproporphyrin recoveries in the range 80 to $105 \%$ and uroporphyrin recoveries of 59 to $97 \%$ using a solvent extraction procedure. Fernandez, Henry and Goldenberg also using a solvent extraction procedure reported recoveries of 90 to $106 \%$ for coproporphyrin and 79 to $109 \%$ for uroporphyrin. Martinez and Mills ${ }^{8}$ using ion-exchange resin method achieved coproporphyrin recoveries of 82 to $106 \%$ while uroporphyrin recovery varied from 87 to $101 \%$.

The recovery figures for the proposed method are much lower than those in the literature for coproporphyrins and slightly lower for uroporphyrins but this should be judged in conjunction with the speed and simplicity of the procedure relative to the other methods quoted. In porphyric urines while the relative proportions of the raised fractions may differ depending on the method used, the proposed method will indicate the type of porphyria present with similar efficiency to Rimington's method. Thus this simple rapid method provides information of equivalent clinical value to that of the more complex and timeconsuming multiple solvent extraction method. The proposed method offers to the smaller laboratory the means to perform urinary porphyrin analysis which might not previously have been considered feasible.

\section{References}

' Haining RG, Hulse T, Labbe RF. Rapid porphyrin screening of urine, stool and blood. Clin Chem 1969;15:460-6.

2 Rimington C. Quantitative determination of porphobilinogen and porphyrins in urine and porphyrins in faeces and erythrocytes. ACP Broadsheet 70, 1971.

${ }^{3}$ With TK, Pedersen JS. Ion exchange analysis of porphyrins in urine. Scand J Clin Lab Invest 1978;38:279-89.

4 Rimington C. Spectral-absorption coefficients of some porphyrins in the Soret-band region. Biochem J 1960;75:620-3.

${ }^{5}$ Fogstrup J, With TK. Urinary total porphyrins by ion exchange analysis: reference values for the normal range and remarks on preformed porphyrins in acute porphyria urine. J Clin Pathol 1979;32:109-12.

- Fernandez AA, Henry RJ, Goldenberg H. Assay of urinary porphyrins. Evaluation of extraction methods and choice of instruments. Clin Chem 1966;12:463-74.

${ }^{7}$ With TK. Quantitative and fractional porphyrin analysis in urine. Clin Biochem 1968;2:97-104.

* Martinez CA, Mills GC. Spectrophotofluorimetric determination of porphyrins in urine. Clin Chem 1971;17:199-205.

Requests for reprints to: Dr TG Brien, Dept. of Pathology, University College, Earlsfort Terrace, Dublin 2, Ireland. 